\title{
Diagnosis of holoprosencephaly in the first trimester
}

\section{Shweta Paliwal*, Chanchal Singh, Nikhil Gholkar, Anita Kaul}

Apollo Centre for Fetal Medicine, Indraprastha Apollo Hospitals, New Delhi, India

Received: 16 October 2013

Accepted: 27 October 2013

\author{
*Correspondence: \\ Dr. Shweta Paliwal, \\ E-mail: shweta@saimsonline.com
}

(C) 2013 Paliwal S et al. This is an open-access article distributed under the terms of the Creative Commons Attribution Non-Commercial License, which permits unrestricted non-commercial use, distribution, and reproduction in any medium, provided the original work is properly cited.

\section{ABSTRACT}

We present a case of alobar holoprosencephaly diagnosed antenatally at 12 weeks gestation. Early diagnosis of such lethal malformation is important so that the parents have an option for termination at an early gestational age minimizing maternal morbidity and social impact on the family.

Keywords: Holoprosencephaly, First trimester, Early diagnosis

\section{INTRODUCTION}

Holoprosencephaly is a spectrum of abnormalities of intracranial and mid facial development. It occurs due to incomplete septation and development of the prosencephalon during early embryogenesis. Based on the severity of cerebral abnormality it has been divided as alobar, semilobar and lobar holoprosencephaly with alobar being the most severe and lobar variety is being the mildest form. Another milder form known as the middle interhemispheric variant has also been described. Perinatal mortality is common in the severe types whereas children affected by the milder subtypes have associated neurological and endocrine disorders.

\section{CASE REPORT}

A 24 year old G2P0 was referred to our center at 12 weeks with a diagnosis of anencephaly. Ultrasound was done using Voluson E8 (GE Healthcare, Milwaukee, WI, USA) with convex abdominal 4-8 MHz transducer and 6$12 \mathrm{MHz}$ transvaginal probe. There was a single live fetus with abnormal facial profile (Figure 1). The butterfly shaped choroid plexus were not visualized.

The axial section at the level of biparietal diameter showed a single sickle shaped ventricle with fused thalami suggestive of alobar variety of holoprosencephaly (Figure 2). There was no associated fetal abnormality.
There was no history of maternal diabetes or any drug intake in the pregnancy. The couple opted to terminate the pregnancy and declined karyotyping.

We emphasize the importance of early diagnosis of such lethal abnormalities so that an early option of termination may be offered thereby minimizing the aftermath of late termination of pregnancy. This is further aided by the use of transvaginal sonography and thus in any suspicious case a transvaginal scan must be done to make a definitive diagnosis.

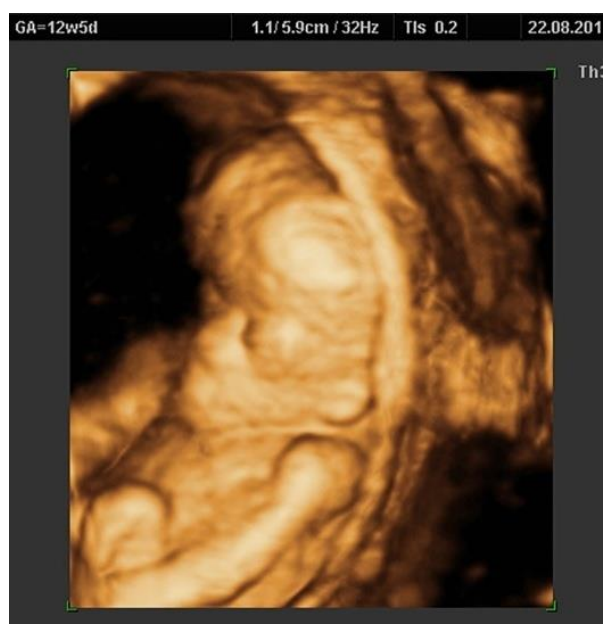

Figure 1: 3D image showing facial dysmorphism. 


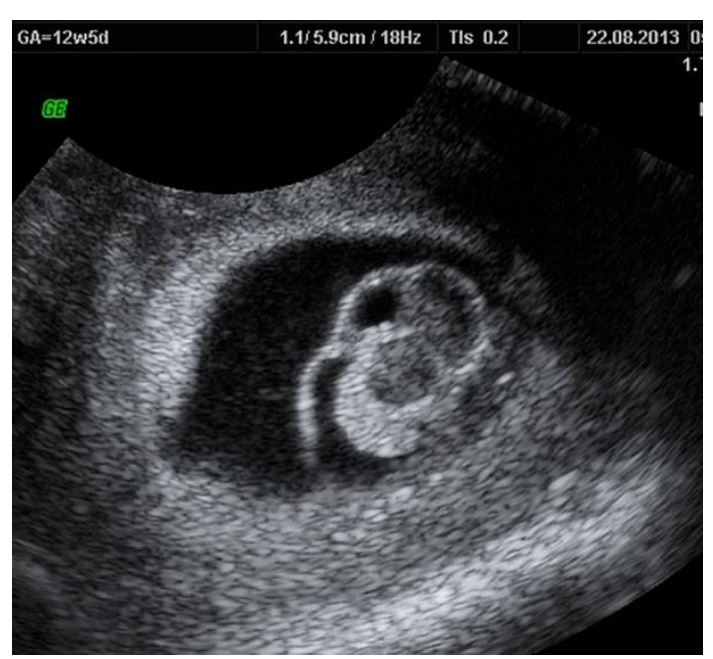

Figure 2: Axial section of fetal brain showing alobar holoprosencephaly.

\section{DISCUSSION}

The incidence of holoprosencephaly is 1.3-1.7/10000 of all pregnancies. ${ }^{1}$ It results from incomplete septation of the embryonic forebrain, the prosencephalon. Most fetuses have some additional abnormal ultrasound finding. The most typical finding in such cases is a facial anomaly which includes hypotelorism, proboscis, cleft lip and palate and an abnormal facial profile. The other common defects can be renal anomalies, postaxial polydactyly, cardiovascular anomalies and omphalocoele. Alobar and semilobar variety can be easily diagnosed antenatally and can be differentiated by the presence of posterior midline echo in the semilobar variety. The manifestations in the lobar type may be very mild and include absent cavum septum pellucidum and variable enlargement of the lateral ventricles.

Etiology includes genetic causes, environmental factors or both. The most common chromosomal abnormality associated with it is Trisomy 13. It is also associated with del 13p, del 18q, dup 3p and del 7. Monogenic inheritance has also been described as autosomal recessive and autosomal dominant fashion. Autosomal recessive form has a severe manifestation and when inherited in autosomal dominant fashion, because of incomplete penetrance and variable expression it may have subtle manifestations. Almost one fourth cases are associated with genetic syndromes like Smith- Lemli Opitz syndrome, Pallister Hall syndrome and Velocardiofacial syndrome. ${ }^{2}$ Recognized environmental factors include insulin dependent maternal diabetes and alcoholism. However drugs like retinoic $\mathrm{acid}^{3}$ and methotrexate ${ }^{4}$ have also been implicated.

The differential diagnosis includes hydrancephaly, porencephaly and severe forms of hydrocephalus. A fetal karyotype should be offered in all cases and chromosomal rearrangements should be looked for in euploid fetuses by means of molecular diagnostic techniques. In non syndromic holoprosencephaly the four common gene mutations are tested (SHH, ZIC2, SIX 3 and TGIF). The recurrence risk in subsequent pregnancies is 1 percent if it is due to a karyotypic abnormality and is much higher if either parents are carriers of a balanced translocation. If either parent has a some phenotypic abnormality it could indicate an autosomal dominant form with a recurrence risk as high as $50 \%$. In all cases the minimum workup should include a detailed family history, karyotype, fetal autopsy and DNA banking. Alobar form of holoprosencephaly is lethal and given the heterogenous etiology, associated chromosomal defects and the variable recurrence risks, an effort to search for a definitive diagnosis should be made in all cases.

\section{REFERENCES}

1. Ong S, Tonks A, Woodward ER, Wyldes MP, Kilby MD. An epidemiological study of holoprosencephaly from a regional congenital anomaly register: 1995-2004. Prenat Diagn 2007;27:340-347.

2. Cohen MM Jr. Holoprosencephaly: clinical, anatomic, and molecular dimensions. Birth Defects Res A Clin Mol Teratol 2006;76:658-673.

3. De Wals P, Bloch D, Calabro A, Calzolari E, Calabro A, et al. Association between holprosencephaly and exposure to topical retinoids. Results of EUROCRAT survey. Paediatr Perinat Epidemiol 1991;5:445-7.

4. Corona -Rivera JR et al. Am J Med Genet A 2010, Jul;152(A)7:1741-6.

DOI: $10.5455 / 2320-1770$. ijrcog20131257

Cite this article as: Paliwal S, Singh C, Gholkar N, Kaul A. Diagnosis of holoprosencephaly in the first trimester. Int J Reprod Contracept Obstet Gynecol 2013;2:735-6. 